\title{
Polyfunctionality and inflectional economy
}

\author{
GREgory StumP
}

\begin{abstract}
One compelling kind of evidence for the autonomy of a language's morphology is the incidence of inflectional polyfunctionality, the systematic use of the same morphology to express distinct but related morphosyntactic content. Polyfunctionality is more complex than mere homophony. It can, in fact, arise in a number of ways: as an effect of rule invitation (wherein the same rule of exponence serves more than one function by interacting with other rules in more than one way), as an expression of morphosyntactic referral, as the effect of a rule of exponence realizing either a disjunction of property sets or a morphomic property set, or as the reflection of a morphosyntactic property set's cross-categorial versatility. I distinguish these different sources of polyfunctionality in a formally precise way. It is inaccurate to see polyfunctionality as an ambiguating source of grammatical complexity; on the contrary, by enhancing the predictability of a language's morphology, it may well enhance both the memorability of complex inflected forms and the ease with which they are processed.
\end{abstract}

\section{Introduction}

In the domain of inflectional morphology, polyfunctionality is the use of the same morphology in the expression of distinct morphosyntactic property sets. Inflectional polyfunctionality is observable both within and across paradigms and even within individual word forms. It is not, in general, a marginal or exceptional phenomenon, but is often tightly integrated into an inflectional system's structure. It is in some ways a paradoxical phenomenon: on one hand, it contributes to an inflectional system's complexity insofar as it sometimes entails morphological ambiguity; on the other hand, it contributes to an inflectional system's

LiLT Volume 11, Issue 3, December 2014.

Theoretical and Computational Morphology: New Trends and Synergies.

Copyright (C) 2014, CSLI Publications. 
economy insofar as it allows a small number of exponents to express a large number of morphosyntactic distinctions, and in some circumstances heightens the predictability of unencountered word forms as well as the frequency of particular word forms or formatives (hence, presumably, their memorability or ease of processing).$^{1}$

Inflectional polyfunctionality may arise from simple homophony: in such instances, two or more distinct inflectional exponents happen to be phonologically identical while differing in their morphosyntactic content. For example, the suffix $-s$ might be seen as exhibiting this trivial kind of polyfunctionality in the English sentence John like-s pear-s: the first instance of this suffix identifies the third-person singular present indicative form of the verb like, while the second instance identifies the plural form of the noun pear. In an inferential-realizational ${ }^{2}$ theory of morphology, this sort of polyfunctionality may be seen as the effect of two or more rules of exponence that introduce the same morphology for the expression of different content, as in Figure 1.

Thus, suppose (a) that rules of exponence have the format in (1), where $\mathrm{X}$ is a metalinguistic variable over stems, $\mathrm{C}$ is a category of stems, $\tau$ is a morphosyntactic property set, and $f$ is a morphological operation; (b) that a rule in this format is applicable to the pairing $\langle\mathrm{Z}, \sigma\rangle$ of a stem $\mathrm{Z}$ with a morphosyntactic property set $\sigma$ if and only if $\mathrm{Z}$ belongs to $\mathrm{C}$ and $\tau$ is a subset of $\sigma$; and (c) that the result of applying a rule in this format to $\langle\mathrm{Z}, \sigma\rangle$ is the pairing $\langle f(\mathrm{Z}), \sigma\rangle$. In that case, the

\footnotetext{
${ }^{1}$ In writing this paper, I have benefited from discussions with Olivier Bonami and Berthold Crysmann; I also received very helpful suggestions from two anonymous referees.

I employ the following abbreviations:

$$
\begin{array}{lll}
\text { abl }=\text { ablative case } & \text { obj }=\text { object } & \text { REL = relativized argument } \\
\text { dat }=\text { dative case } & \text { pers = personal gender } & \text { sbj= subject } \\
\text { fut }=\text { future tense } & \text { pl = plural } & \text { SBJ }=\text { subject inflection } \\
\text { gnl }=\text { general tense } & \text { prs = present tense } & \text { sbjv = subjunctive mood } \\
\text { IFD = Identity Function Default } & \text { psm = possessum } & \text { sg = singular } \\
\text { ind = indicative mood } & \text { psr = possessor } & \\
\text { neg }=\text { negative polarity } & \text { pst = past tense } &
\end{array}
$$

${ }^{2}$ An inferential theory of inflectional morphology is one that represents the relation between morphosyntactic property sets and their inflectional exponents as rules by which fully inflected word forms are inferrable from their stems; inferential theories therefore differ from lexical ( $\neq$ lexicalist!) theories, in which relations between morphosyntactic property sets and their exponents are stated in the lexicon. A realizational theory of inflectional morphology is one that treats a word's association with a particular morphosyntactic property set as a precondition for its inflectional realization; realizational theories therefore differ from incremental theories, in which a word acquires its morphosyntactic properties as a concomitant of acquiring its inflectional markings. See Stump (2001) for arguments for preferring inferential-realizational theories of inflectional morphology.
} 
FIGURE 1 Inflectional polyfunctionality arising from simple homophony

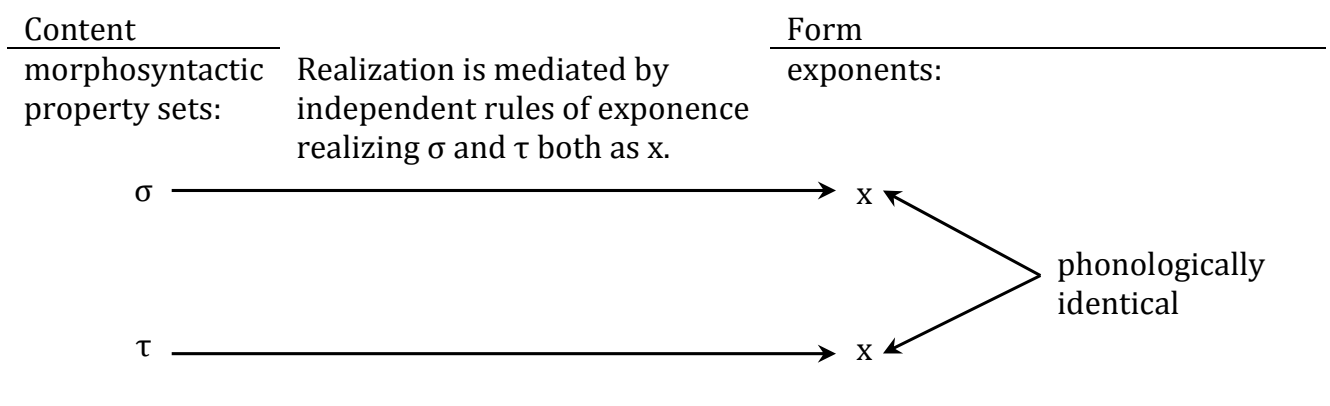

trivial polyfunctionality of English $-s$ might be attributed to the pair of rules in (2).

(1) Rule of exponence: $\mathrm{X}, \mathrm{C}, \tau \rightarrow f(\mathrm{X})$

(2) Two rules of exponence in English

(a) X, Noun, $\{\mathrm{pl}\} \rightarrow \mathrm{X} s$

(b) $\mathrm{X}$, Verb, $\{3 \mathrm{sg}$ prs ind $\} \rightarrow \mathrm{X} s$

The question naturally arises whether ALL polyfunctionality should simply be seen as involving simple homophony of the sort exemplified in (2). The response that I propose here is: definitely not. In a carefully articulated theory of inflection, polyfunctionality may arise in several ways, and in many instances involves exponents that are not merely alike in form, but are in fact introduced by the very same rule of exponence. Three kinds of evidence lead to this conclusion. First, there are phonologically identical inflectional exponents that, despite differing in their content, are not merely alike in form, but participate in the same idiosyncratic allomorphy; treating these as distinct morphological markings fails to account for their shared morpho(phono)logical idiosyncrasy. Second, there are phonologically identical inflectional exponents that, despite their different content, nevertheless share a part of their content; treating these as distinct morphological markings fails to account for their overlap in content. And third, there are phonologically identical exponents that, though differing in content, nevertheless conform to a larger, systematic pattern of identity observable over a range of exponents; treating these as distinct markings that happen to coincide in form fails to account for this larger pattern.

Given any polyfunctional exponent $\mathrm{p}$, it is important to ask: where are p's contrasting functions found? Fundamentally, there are three possibilities:

- First, p's contrasting functions may be associated with different 
layers of words' inflectional morphology. For example, the same affix may express distinct but related functions in more than one affix position. In inferential-realizational theories of inflection, it is customary to model each layer in a word's inflectional marking by means of a dedicated block of realization rules. Thus, this first type of polyfunctionality might be formalized as a single rule of exponence serving distinct but related functions in more than one rule block. I shall refer to such instances as involving polyfunctionality across blocks.

- Second, p's contrasting functions may be associated with different word forms realizing a given lexeme. This variety of polyfunctionality might be modeled as a rule of exponence serving distinct but related functions in the realization of distinct cells in a lexeme's paradigm. I shall therefore refer to these as instances of polyfunctionality across cells.

- Finally, p's contrasting functions may be associated with word forms realizing cells in the paradigms of lexemes belonging to distinct categories, including syntactic categories but also subcategories of individual syntactic categories. I shall refer to such instances as involving polyfunctionality across categories.

I consider cases of each of these sorts, for each of which I propose a different theoretical interpretation. In none of these cases should polyfunctionality be equated with mere homophony, but must instead be seen as an intrinsic property of particular rules of exponence. In $\S 2$, I argue that instances of polyfunctionality across blocks involve a phenomenon of rule invitation wherein rules of referral realizing distinct but related content refer the realization of that content to the same rule of exponence in different rule blocks.

In $\S 3$, I argue that instances of polyfunctionality across cells involve two distinct phenomena. One class of cases involves referral: in these cases, the exponence of one or more property sets in an inflectional paradigm patterns after that of some other property set by means of a rule of referral ( $\$ 3.1)$. The complementary class of cases involves shared exponence: in these cases, two or more property sets have the same exponence, but there is no basis for regarding one of the property sets as providing this exponence as a model for that of the other sets; instead, a single rule of exponence causes two or more contrasting property sets to have the same exponence (§3.2). Polyfunctionality across cells, whether it involves referral or shared exponence, may involve out-and-out syncretism among the cells involved, but it need not do so; it may simply involve a single similar layer of morphology in the 
cells' inflectional realizations.

In $\S 4, \mathrm{I}$ argue that polyfunctionality across categories may arise as an effect of the cross-categorial recurrence of certain morphosyntactic properties. Cross-categorial recurrence is the incidence of one or more of the same properties in the morphosyntactic property sets associated with lexemes belonging to different categories. For example, a noun specified for a first-person singular possessor may share one or more of its inflectional exponents with a verb specified for a first-person singular subject; in that case, the exponents involved are polyfunctional.

In order to articulate this multifaceted conception of polyfunctionality in a precise way, I adopt certain theoretical assumptions from Stump (2001). First, I assume that a lexeme L's inflectional paradigm is a set of cells, where each cell is the pairing $\langle\mathrm{Z}, \sigma\rangle$ of L's root Z with a morphosyntactic property set $\sigma$ for which $\mathrm{Z}$ is inflectable; the realization of a given cell $\langle\mathrm{Z}, \sigma\rangle$ is the pairing $\langle w, \sigma\rangle$ of the corresponding fully inflected word form $w$ with $\sigma$. In a given language $\ell$, the function from cells to their realizations is $\ell$ 's paradigm function. On this view, the definition of a language's inflectional morphology is equated with the definition of its paradigm function PF. This definition consists of a number of clauses, each pertaining to the realization of a different class of cells. In cases in which the paradigm of a lexeme $\mathrm{L}$ contains a cell $\langle\mathrm{Z}, \sigma\rangle$ whose realization is wholly irregular, the value of $\mathrm{PF}(\langle\mathrm{Z}, \sigma\rangle)$ (= the realization of $\langle\mathrm{Z}, \sigma\rangle)$ is simply listed in L's lexical entry; otherwise, the value of $\operatorname{PF}(\langle\mathrm{Z}, \sigma\rangle)$ is defined in terms of more specific realization rules. These are of two types.

Rules of exponence are as in (1). Rules of referral have the format in (3), where $\mathrm{C}$ is a category of stems, $\tau$ is a morphosyntactic property set, $\mathrm{A}$ is a rule block and $f$ is a function in the set of morphosyntactic property sets. A rule in this format is applicable to the pairing $\langle\mathrm{Z}, \sigma\rangle$ of a stem $\mathrm{Z}$ with a morphosyntactic property set $\sigma$ if and only if $\mathrm{Z}$ belongs to $\mathrm{C}$ and $\tau$ is a subset of $\sigma$. The result of applying a rule in this format to $\langle\mathrm{Z}, \sigma\rangle$ is $\left\langle\mathrm{Z}^{\prime}, \sigma\right\rangle$, where $\left\langle\mathrm{Z}^{\prime}, f(\sigma)\right\rangle$ is the result of applying the most narrowly defined rule in Block $A$ that is applicable to $\langle\mathrm{Z}, f(\sigma)\rangle$. (Below, I use the notation $[\mathrm{n}:\langle\mathrm{Z}, \sigma\rangle]$ to represent the result of applying the most narrowly defined rule in Block $\mathrm{n}$ that is applicable to $\langle\mathrm{Z}, \sigma\rangle$.) An illustrative example of a rule of referral is (4a), which specifies that an imperative verb form is inflected just as the corresponding present indicative verb form is inflected in Block i. Rule (4a) applies (for example) to the cell specified in (4b), and on the assumption that $(4 \mathrm{c})$ is the narrowest rule in Block i that is applicable to $\left\langle/ \mathrm{ma}_{3} /,\{2 \mathrm{pl}\right.$ present indicative $\left.\}\right\rangle$, the result of applying (4a) to $(4 \mathrm{~b})$ is $(4 \mathrm{~d})$. 
(3) Rule of referral: $\mathrm{C}, \sigma \rightarrow \mathrm{A}, f$

(4) a. Verb, imperative $\rightarrow \mathrm{i}, f: \sigma \rightarrow[\sigma \backslash\{$ imperative $\}] \cup\{$ prs ind $\}$

b. $\langle/ \mathrm{ma} 3 /,\{2 \mathrm{pl}$ imperative $\}\rangle$

c. $/ \mathrm{X} /$, Verb, $\{2 \mathrm{pl}\} \rightarrow / \mathrm{Xe} /$

d. $\langle/$ mãze/, $\{2 \mathrm{pl}$ imperative $\}\rangle$

This formal framework makes it possible to model a variety of sources for inflectional polyfunctionality beyond that of simple homophony.

\section{Polyfunctionality across blocks: Rule invitation}

In the definition of a word form, a rule of exponence ordinarily participates as a member of a single rule block. There are, however, many cases in which the same rule of exponence applies in more than one block, performing different (but related) functions according to where it applies. In such cases, the marking that the rule introduces is polyfunctional, expressing one kind of content in the layer of morphology defined by one block and a different (but related) kind of content in the layer defined by another block. This source of polyfunctionality is represented schematically in Figure 2.

FIGURE 2 Polyfunctionality across blocks arising from rule invitation

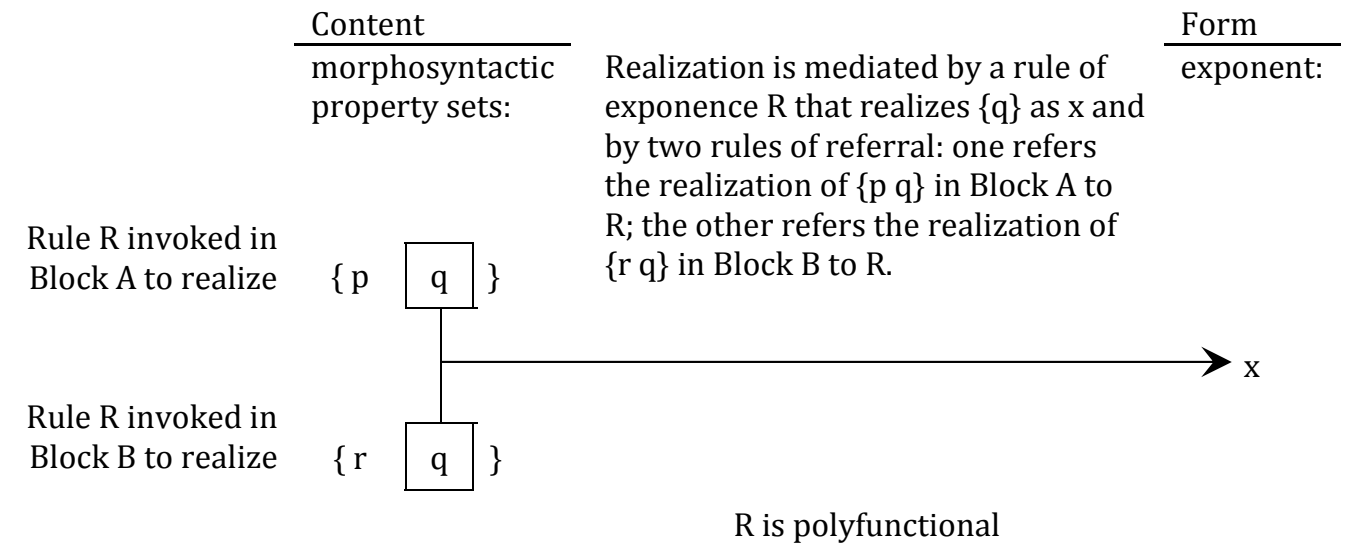

There are cases in which the same rule of exponence applies in more than one block in the definition of the same word form. In Swahili, for example, a rule realizing verbal concord for noun class sometimes applies twice, realizing object agreement as a member of one rule block and subject agreement as a member of another; thus, in (5), the subject and object arguments both belong to the ki-vi gender, entailing two instances of the verbal concord $k i$-. 
(5) ki-faru ki-li-ki-sukuma ki-kapu.

NC-rhinoceros SBJ.NC-TNS-OBJ.NC-push NC-basket

The rhinoceros pushed the basket.

More often, however, polyfunctionality across blocks is observable only by comparing distinct word forms; in such cases, polyfunctionality across blocks coincides with polyfunctionality across cells. Swahili presents an example of this sort as well (Ashton 1944: 70ff, 112, 119f). In the indicative inflection of Swahili verbs, the usual expression of negation is the prefix $h a$ - exemplified in Table 1.a-c. In certain circumstances, however, negation is instead expressed by a prefix si- : (a) in subjunctive verb forms (Table 1.d, e); (b) in relative verb forms (Table1.f, g); and (c) in first-person singular nonrelative indicative forms (where $s i$ - supplants the first-person singular subject-agreement prefix $n i$ - as well as the expected negative prefix $h a-$; Table $1 . h-\mathrm{j}$ ). In nonrelative indicative forms, $s i$ - is a kind of portmanteau, overriding both the appearance of $h a$ - in affix position iv and that of $n i$ - in affix position iii (the position of subject-agreement prefixes); in that role, $s i$ - precedes any tense prefix - that is, it precedes affix position ii. In relative and subjunctive forms, by contrast, it occupies position ii, overriding the appearance of any tense prefix and following the subjectagreement prefix.

TABLE 1 The negative prefixes $h a$ - and si- in Swahili verb forms

\begin{tabular}{|c|c|c|c|c|c|c|c|}
\hline & \multicolumn{3}{|c|}{ POSITION } & \multicolumn{2}{|c|}{ CLASSES } & \multirow[b]{2}{*}{ 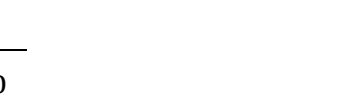 } \\
\hline & & iv & iii & ii & $\mathrm{i}$ & Stem & \\
\hline & $\langle$ SOMA, $\{$ neg SBJ: $\{1 \mathrm{pl}\}$ ind pst $\}\rangle:$ & ha- & tu- & $k u-$ & & som & - $a$ 'we didn't read' \\
\hline & $\langle$ SOMA, $\{$ neg SBJ: $\{1 \mathrm{pl}\}$ ind fut $\}\rangle:$ & ha- & $t u-$ & ta- & & som & - $a$ 'we won't read' \\
\hline c. & $\langle$ SOMA, $\{$ neg SBJ: $\{1 \mathrm{pl}\}$ ind gnl $\}\rangle:$ & ha- & tu- & & & som & $-i$ 'we don't read' \\
\hline d. & $\langle$ SOMA, $\{$ neg SBJ: $\{1$ pl $\}$ sbjv $\}\rangle:$ & & tu- & si- & & som & $-e$ 'that we may not read' \\
\hline e. & $\langle$ SOMA, $\{$ neg SBJ: $\{1$ sg $\}$ sbjv $\}\rangle:$ & & $n i-$ & si- & & som & $-e$ 'that I may not read' \\
\hline f. & $\langle$ SOMA, $\{$ neg SBJ: $\{3$ pl pers $\}$ REL:\{pers pl $\}\}\rangle:$ & & $w a-$ & si- & $o-$ & som & - $a$ 'who do not read' \\
\hline g. & $\langle$ SOMA, $\{$ neg SBJ: $\{3$ sg pers $\}$ REL:\{pers sg $\}\}\rangle:$ & & $a-$ & si- & $y e-$ & som & - $a$ 'who does not read' \\
\hline h. & $\langle$ SOMA, $\{$ neg SBJ: $\{1$ sg $\}$ ind pst $\}\rangle:$ & & $i-$ & $k u-$ & & som & - $a$ 'I didn't read' \\
\hline & $\langle$ SOMA, $\{$ neg SBJ: $\{1$ sg $\}$ ind fut $\}\rangle:$ & $S$ & $i-$ & ta- & & som & - $a$ 'I won't read' \\
\hline & $\langle$ SOMA, $\{$ neg SBJ: $\{1$ sg $\}$ ind gnl $\}\rangle:$ & $s$ & $i-$ & & & som & $-i$ 'I don't read' \\
\hline
\end{tabular}

To account for the polyfunctionality of the $s i$ - rule, one can postulate seven affixal rule blocks ${ }^{3}$ :

\footnotetext{
${ }^{3}$ From a theoretical standpoint, nothing whatever hinges on the names given to
} 
- Block 0 : the rules for a verb form's suffixal vowel;

- Block i : rules of relative affixation (expressing the gender and number of a relative verb form's relativized argument);

- Block ii : rules of tense/mood prefixation as well as a rule of referral invoking the $s i$ - rule;

- Block iv iii : a portmanteau block housing a rule of referral invoking the si-rule; unless this rule of referral applies, [ iv_iii : < $\mathrm{X}, \sigma\rangle]$ defaults to [iv : [ iii : $\langle\mathrm{X}, \sigma\rangle]]$, in accordance with the Function Composition Default (Stump 2001: 142);

- Block iii : rules of subject-agreement prefixation;

- Block iv : the negative indicative rule of $h a$ - prefixation; and

- Block $\mathrm{v}$ : the negative rule of $s i$ - prefixation.

The rules housed by each of these blocks are formulated in (6b) below.

Ordinarily, a word form's exponence is defined through the successive application of Blocks 0, i, ii, and iv_iii, as specified in clause (6a) in the definition of the Swahili paradigm function ${ }^{4}$. But in the inflection of negative subjunctive or relative forms, the rule of referral in Block ii refers to the Block $\mathrm{v}$ rule of si-prefixation; and in the inflection of first-person singular negative indicative forms, the rule of referral in Block iv_iii also refers to the Block v rule, overriding the Function Composition Default.

(6) Formal analysis of Swahili negative inflections

(a) Paradigm function:

$$
\operatorname{PF}(\langle\mathrm{Z}, \sigma\rangle)=[\text { iv_iii : }[\text { ii : }[\mathrm{i}:[0:\langle\mathrm{Z}, \sigma\rangle]]]]
$$

a language's rule blocks. The blocks listed here are named with Roman numerals because of their logical connection to the similarly named affix position classes in Table 1 (whose names in turn reflect their linear order). But the definition of the paradigm function in (6a) provides all of the necessary information about the interaction of rule blocks, and this definition in no way depends on the particular choice of names for these blocks; it only requires that they have distinct names.

${ }^{4}$ For the sake of expository simplicity, I here ignore two complications that are not directly relevant to the polyfunctionality of si-prefixation. First, Swahili verbs sometimes have prefixes coding the agreement properties of an object, as in (5); these affixes necessitate the postulation of an additional position class situated immediately before a verb's stem. Second, the relative prefixes in Block i appear as suffixes in relative verb forms that are tenseless and affirmative. For detailed accounts of Bantu verb morphology that account for both of these facts (and do so in ways that are fully consonant with the present analysis of si-prefixation), see Stump (2001: 144ff, 2013.) 
(b) Realization rules

\begin{tabular}{|c|c|c|c|}
\hline Block 0 & & Block iii & \\
\hline$X$, Verb, \{\} & $\rightarrow \mathrm{X} a$ & $\mathrm{X}$, Verb, $\{1 \mathrm{sg}\}$ & $\rightarrow n i \mathrm{X}$ \\
\hline $\mathrm{X}$, Verb, $\{$ gnl $\}$ & $\rightarrow \mathrm{X} i$ & $\mathrm{X}$, Verb, $\{2 \mathrm{sg}\}$ & $\rightarrow u \mathrm{X}$ \\
\hline $\mathrm{X}$, Verb, $\{$ sbjuv $\}$ & $\rightarrow \mathrm{X} e$ & $X$, Verb, $\{3$ sg pers $\}$ & $\rightarrow a \mathrm{X}$ \\
\hline & & $\mathrm{X}$, Verb, $\{1 \mathrm{pl}\}$ & $\rightarrow t u X$ \\
\hline Block i & & $\mathrm{X}$, Verb, $\{2 \mathrm{pl}\}$ & $\rightarrow m \mathrm{X}$ \\
\hline X, Verb, \{REL:\{pers sg\}\} & $\rightarrow y e \mathrm{X}$ & $X$, Verb, $\{3$ pl pers $\}$ & $\rightarrow w a X$ \\
\hline $\mathrm{X}$, Verb, $\{$ REL: $\{$ pers pl $\}\}$ & $\rightarrow o \mathrm{X}$ & etc. & \\
\hline & & Block iv & \\
\hline Block ii & & $X$, Verb, $\{$ neg ind $\}$ & $\rightarrow h a \mathrm{X}$ \\
\hline$X$, Verb, $\{$ neg pst $\}$ & $\rightarrow k u X$ & & \\
\hline $\mathrm{X}$, Verb, $\{\mathrm{pst}\}$ & $\rightarrow \operatorname{liX}$ & Block v & \\
\hline$X$, Verb, $\{$ fut $\}$ & $\rightarrow \operatorname{taX}$ & $\mathrm{X}$, Verb, $\{\mathrm{neg}\}$ & $\rightarrow \operatorname{siX}$ \\
\hline $\begin{array}{l}\text { Verb, }\{\text { neg }[\text { sbjv } \vee \text { REL: } \tau]\} \\
\text { etc. }\end{array}$ & $\rightarrow \mathrm{v}, f: \sigma \rightarrow \sigma$ & & \\
\hline & & & \\
\hline Verb, $\{1$ sg neg ind $\}$ & $\rightarrow \mathrm{v}, f: \sigma \rightarrow \sigma$ & & \\
\hline
\end{tabular}

According to this analysis, the Block v rule of $s i$ - prefixation simply realizes negation. But when this rule applies as a referral from Block ii in the realization of a verb form $w$, its application additionally implies that $w$ is either a subjunctive or a relative verb form; and when it applies as a referral from the portmanteau Block iv_iii, its application additionally implies that $w$ is a first-person singular indicative form. The rule of si- prefixation is therefore polyfunctional across blocks.

\section{Polyfunctionality across cells}

Polyfunctionality across cells is a varied phenomenon. Some polyfunctional exponents are isolated: their use in expressing different sets of properties in the realization of different paradigm cells is unparalleled elsewhere in the system to which they belong. By contrast, many languages exhibit classes of polyfunctional exponents whose members manifest a single, general pattern of morphological versatility. In either case, a polyfunctional exponent may cause the cells in its domain to be fully syncretic or it may cause them to be only partially alike in their realization. And in either case, the polyfunctionality may involve referral or shared exponence. Consider the details of this latter distinction.

\subsection{Polyfunctionality across cells as an effect of referral}

The exponence of one morphosyntactic property set may pattern after that of a contrasting property set, as in Figure 3.

Consider, for example, the declension of Latin adjectives. If a Latin adjective has an ablative singular form in $-\overline{1}$, its dative singular form is inevitably identical (e.g. dat./abl. felīcī 'happy'); the reverse, however, 
FIGURE 3 Polyfunctionality across cells as an effect of referral

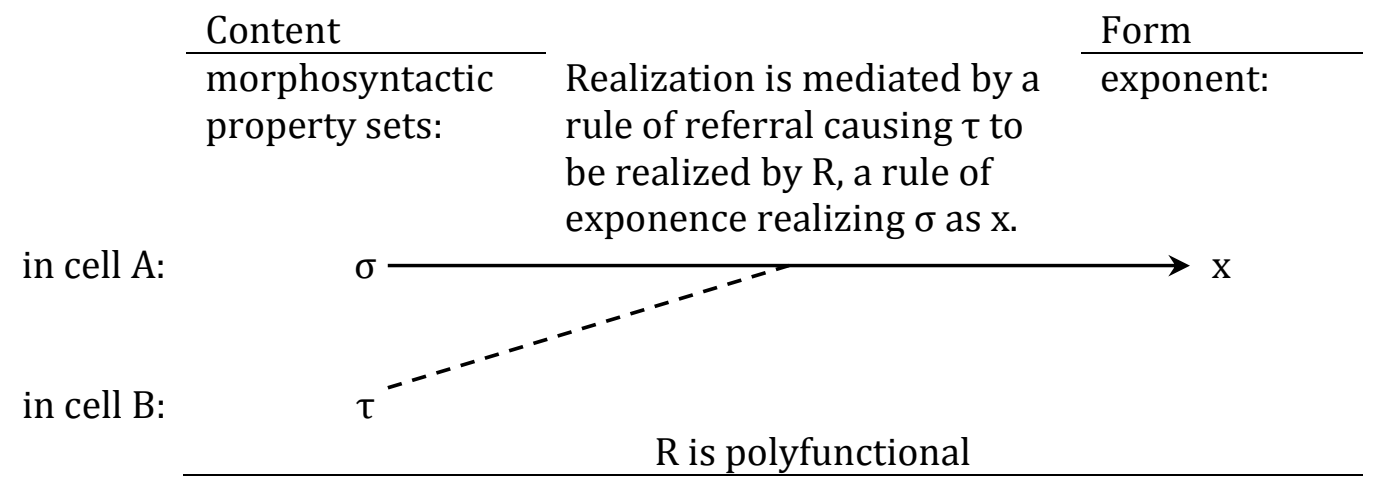

is not invariably true (dat. veterī 'old', abl. vetere). This suggests that the case suffix $\bar{l}$ is primarily an expression of the dative singular and that the expression of the ablative singular sometimes patterns after it. One way of formalizing this sort of asymmetrical polyfunctionality is by means of a rule of referral having the format in (3). In the case at hand, the dative singular suffix $-\overline{1}$ might be introduced in Block i by the default rule of exponence in (7a); the rule of referral in (7b) would then cause $-\overline{1}$ to take on an additional, ablative singular function in the inflection of nominals belonging to a particular subclass $\mathrm{S}$ such that FĒLīX 'happy' $\in \mathrm{S}$ but VETUS 'old' $\notin \mathrm{S}$.

(7) a. X, Nominal, $\{$ dat sg $\} \rightarrow \mathrm{X}_{\bar{l}}$

b. $\mathrm{S},\{\mathrm{ablsg}\} \rightarrow \mathrm{i}, f: \sigma \rightarrow[\sigma \backslash\{\mathrm{abl}\}] \cup\{$ dat $\}$

\subsection{Polyfunctionality across cells as an effect of shared exponence}

Not all cases of polyfunctionality across cells evince the sort of asymmetry exhibited by Latin ablative singulars in $-\overline{1}$. In many instances, a rule of exponence participates in the realization of two or more morphosyntactic property sets no one of which can be plausibly identified as the primary condition on that rule's application. In the simplest cases, symmetrical polyfunctionality of this sort may be formalized as a rule of disjunctive exponence that realizes contrasting property sets by means of one and the same exponent, as in Figure 4. Such rules account for isolated patterns of nondirectional syncretism. There are naturally phenomena that could be analyzed either as involving a rule of disjunctive exponence (as in Figure 4) or as involving two rules that happen to express distinct property sets by means of the same morphology (as in Figure 1). But there are also cases that clearly involve disjunctive exponence rather than simple homophony; these are cases 
in which an affixal exponent exhibits the same idiosyncratic allomorphy in realizing distinct morphosyntactic property sets.

FIGURE 4 Polyfunctionality across cells arising from disjunctive exponence

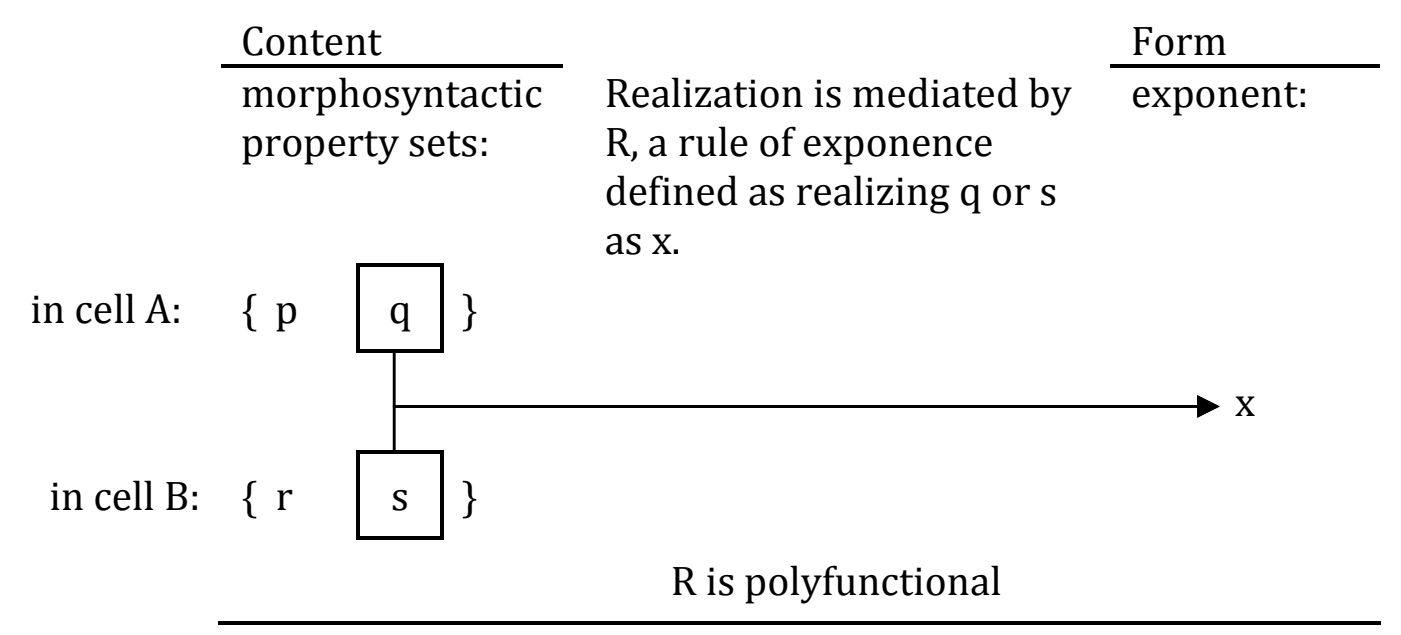

Consider a case of this sort from the Noon language (Niger-Congo; Senegal) in (8). In Noon, the verbal suffix - $u(s)$ expresses passive voice, appearing as $-u$ in word-final position and otherwise as -us; examples (8a-b) illustrate. This same suffix may instead express plural number, as in $(8 \mathrm{c}, \mathrm{d})$. In either function, the $-u(s)$ suffix is supplanted by -uunun in the perfect aspect, as in the perfect passive sentence $(8 \mathrm{e})$ and the plural perfect sentence in (8f). Thus, whether as an expression of passive voice or as an expression of plural number, these suffixes participate in the alternation $-u \sim-u(s) \sim-$ unnun. Because the passive and plural uses of this suffix are not restricted to complementary contexts, ambiguity sometimes arises (M. Soukka, p. c.), as in (8g), whose gloss P ambiguously represents plural agreement or passive voice.

(8) An inflectional suffix in Noon (Niger-Congo; Senegal) (Soukka 2000: 176)
(a) Mi lím-u
ga Padee.
I have.child-PASS in Fandène
'I was born in Fandène.'
(b) Jën-aa ñamsi na maalu.

$$
=\text { nam-us-i }
$$
fish-DEF eat-PASS-HAB with rice
'Fish is eaten (habitually) with rice.'
(c) Beti-caa ham-u ga feet-aa. women-DEF dance-PL at feast-DEF
'The women dance at the feast.' 
(d) Yaal-caa ka'seera Dakaa'. $=\mathrm{kad}$-us-ee-ra

men-DEF leave.for-PL-PAST-PUNCT Dakar

'The men had left for Dakar.'

(e) Jën-aa tóoh ñam-uunun.

fish-DEF all eat-PASS.PERF

'The whole fish has been eaten.'

(f) *Oomaa-caa fool-uunun bes-ii tóoh.

children-DEF run-PL.PERF day-DEF all

'The children have run all day.'

(g) *Pe'-caa ñam-uunun.

goats-DEF eat-P.PERF

Ambiguous: 'The goats have eaten.' /'The goats have been eaten.'

The format for rules of exponence given above in (1) can be straightforwardly extended to accommodate rules of disjunctive exponence by allowing rules of exponence to realize constraints on morphosyntactic property sets (Gazdar et al. 1988) - members of the set $M$ of morphosyntactic property sets closed under the Boolean operations of conjunction, disjunction and complementation. Where $\mathrm{K} \in M$, the rule of exponence in (9) is applicable to the pairing $\langle\mathrm{Z}, \sigma\rangle$ of stem $\mathrm{Z}$ with property set $\sigma$ iff $Z \in C$ and $\sigma$ satisfies $^{5} \mathrm{~K}$; in that case, the result of applying (9) to $\langle\mathrm{Z}, \sigma\rangle$ is $\langle f(\mathrm{Z}), \sigma\rangle$.

(9) $\mathrm{X}, \mathrm{C}, \mathrm{K} \rightarrow f(\mathrm{X})$

In this way, the use of the suffixes $-u(s)$ and -uunun in Noon can be accounted for by the rules of exponence in (10), each of which is intrinsically polyfunctional.

(10) Two rules of exponence for Noon verb inflection

(a) $\mathrm{X}$, Verb, $[\{\mathrm{pl}\} \vee\{$ passive $\}] \rightarrow \mathrm{X} u \mathrm{~S}$

(Sandhi: $\mathrm{S} \rightarrow \emptyset / \ldots \#, \rightarrow s$ otherwise.)

(b) X, Verb, \{perfect $\} \wedge\{[\{\mathrm{pl}\} \vee\{$ passive $\}]\} \rightarrow \mathrm{X}$ uunun

To my knowledge, the two rules of exponence in (10) are the only rules of Noon grammar that make reference to the property-set constraint $[\{\mathrm{pl}\} \vee\{$ passive $\}]$. Some languages do, however, present cases

\footnotetext{
${ }^{5}$ The satisfies relation is recursively defined: where $\sigma$ is a morphosyntactic property set and $\mathrm{K} 1, \mathrm{~K} 2 \in M$,

(i) $\sigma$ satisfies $[\mathrm{K} 1 \wedge \mathrm{K} 2]$ iff $\sigma$ satisfies both $\mathrm{K} 1$ and $\mathrm{K} 2$;

(ii) $\sigma$ satisfies $[\mathrm{K} 1 \vee \mathrm{K} 2]$ iff $\sigma$ satisfies either $\mathrm{k} 1$ or $\mathrm{K} 2$ (or both);

(iii) $\sigma$ satisfies $\neg \mathrm{K} 1$ iff $\sigma$ doesn't satisfy $\mathrm{K} 1$; and

(iv) If $\mathrm{K} 1$ is a morphosyntactic property set, then $\sigma$ satisfies $\mathrm{k} 1$ iff $\mathrm{K} 1 \subseteq \sigma$.
} 
in which the same constraint is invoked repeatedly; in such instances, it is reasonable to regard the constraint as having acquired the status of a morphome - a property having no fixed syntactic or semantic significance but to which rules of morphology are nevertheless sensitive (Aronoff 1994). A particular morphome m may figure in the realization of a class of morphosyntactic property sets that do not constitute a natural class by any syntactic or semantic criterion; in such cases, the rule realizing $\mathrm{m}$ is polyfunctional in that it participates in the realization of an unnatural class of morphosyntactic property sets, as in Figure 5.

FIGURE 5 Polyfunctionality across cells arising from a morphomic property

\begin{tabular}{l} 
Content \\
\hline morphosyntactic \\
property sets:
\end{tabular}

The realization of $\mathrm{q}$ and $\mathrm{s}$ is $\frac{\text { Form }}{\text { exponent: }}$ mediated by a morphomic property m realized as $\mathrm{x}$ by a rule of exponence $\mathrm{R}$.

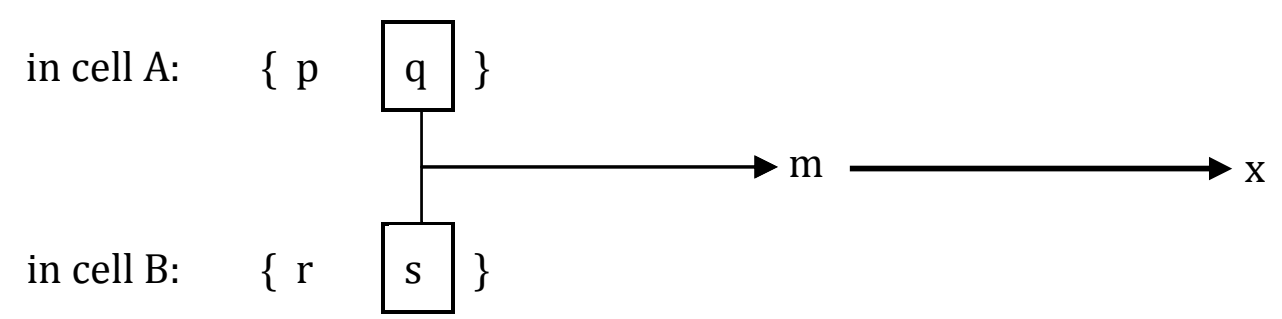

$\mathrm{R}$ is polyfunctional

The Hua language (Trans-New-Guinea) presents a striking example of this sort. In Hua, there are twelve moods, each of which has a set of verb-agreement suffixes expressing a subject's person $\left(1^{\text {st }}, 2^{\text {nd }}, 3^{\text {rd }}\right)$ and number ( $\mathrm{sg}, \mathrm{du}, \mathrm{pl})$. The exponence of these agreement properties is, however, mediated by two morphomic properties: A (= singular in the first and third persons, plural in the second and third persons) and $\mathrm{B}$ (= singular in the second person, plural in the first person). The inventory of agreement suffixes expressing these morphomic properties is given in Table 2; Table 3 presents a sample agreement paradigm, arranged first according to morphosyntactic content and then morphomically.

The morphomes A and B cannot be seen as supplanting properties of person, which must remain available to condition stem ablaut in Hua verbs (for which the relevant rules of exponence are given as Block i in (12b) below); by contrast, the morphomes A and B may be seen as 
TABLE 2 Hua agreement suffixes (Haiman 1980: 48)

\begin{tabular}{|c|c|c|c|c|c|c|c|c|c|c|c|c|}
\hline \multirow[b]{3}{*}{ Properties } & \multirow[b]{3}{*}{ 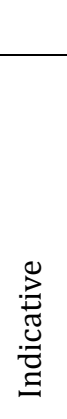 } & \multirow[b]{3}{*}{ 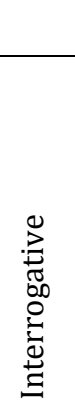 } & \multirow[b]{3}{*}{ 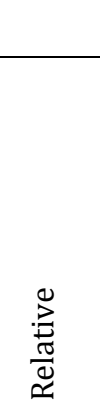 } & \multirow{3}{*}{$\begin{array}{l}0 \\
\stackrel{0}{0} \\
\stackrel{0}{0} \\
\vdots \\
\vdots\end{array}$} & \multirow{3}{*}{ 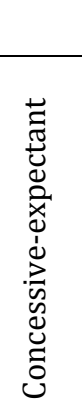 } & \multirow[b]{3}{*}{ 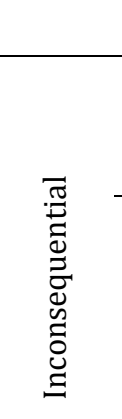 } & \multicolumn{2}{|c|}{ Moods } & \multirow[b]{3}{*}{ 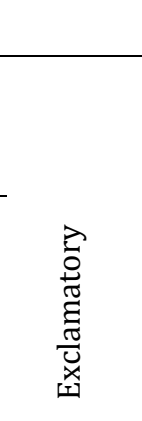 } & \multirow[b]{3}{*}{ 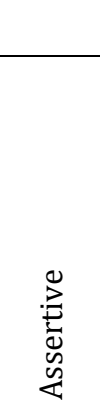 } & & \\
\hline & & & & & & & $\mathrm{Mec}$ & dial & & & \multicolumn{2}{|c|}{ Counterfactual } \\
\hline & & & & & & & 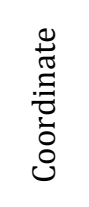 & $\begin{array}{l}\text { 䒕 } \\
\stackrel{\Xi}{0} \\
\overline{0} \\
\stackrel{0}{0} \\
\tilde{\omega}\end{array}$ & & & $\begin{array}{l}\frac{n}{0} \\
\tilde{n} \\
0 \\
0 \\
0\end{array}$ & $\begin{array}{l}\frac{n}{4} \\
\frac{0}{0} \\
0 \\
\frac{2}{4}\end{array}$ \\
\hline$A$ & $-e$ & $-v e$ & $-m a^{\prime}$ & $-m i^{\prime}$ & $-v a$ & -mana & $-g a$ & $-m a$ & -mane & -mae & -hipana & -hine \\
\hline dual & $-2 e$ & -'ve & $-^{\prime}-m a^{\prime}$ & $-'-m i^{\prime}$ & $\therefore-v a$ & -'-mana & $\therefore-g a$ & $\therefore-m a$ & -'-mane & -'-mae & -'-hipana & -'-hine \\
\hline$B$ & $-n e$ & $-p e$ & $-p a^{\prime}$ & $-p i^{\prime}$ & $-p a$ & -pana & $-n a$ & $-p a$ & -pane & $-p a e$ & -sipana & -sine \\
\hline
\end{tabular}

TABLE 3 Interrogative forms of the Hua verb $\mathrm{HU}$ 'do'

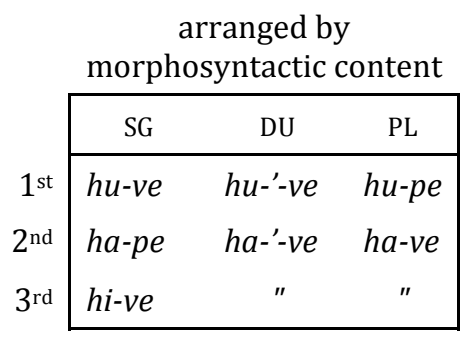

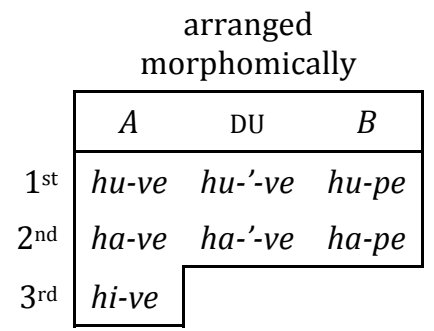

supplanting the properties 'singular' and 'plural', to which Hua verb inflection is not directly sensitive. Thus, the relation between the sets of agreement properties relevant for the syntax and semantics of Hua verb forms and the (partially morphomic) sets of properties relevant for their morphology may be defined as the property-mapping function $\boldsymbol{p} \boldsymbol{m}$ in (11); $\boldsymbol{p} \boldsymbol{m}$ enters directly into clause (12a) of the definition of the Hua paradigm function, allowing the rules of suffixal exponence for Hua verbs to be morphomically conditioned, as in Block iii of (12b). By the definition of $\boldsymbol{p} \boldsymbol{m}$, the morphomes $A$ and $B$ have the same content as the constraints in (13a) and (13b), respectively, but they afford a much more economical formulation of the rules of exponence in Block iii of $(12 b)$.

(11) Mapping from morphosyntactic property sets to partially morphomic property sets in Hua

Where $\rho, \sigma$ are such that

$\rho \in\{\{\mathrm{x} \mathrm{y}\}: \mathrm{x} \in\{1,2,3\}$ and $\mathrm{y} \in\{\mathrm{sg}$, dual, $\mathrm{pl}\}\}$ and $\rho \subset \sigma$, $\boldsymbol{p} \boldsymbol{m}(\rho)$ has the value below and $\boldsymbol{p} \boldsymbol{m}(\sigma)=[\sigma \backslash \rho] \cup \boldsymbol{p} \boldsymbol{m}(\rho)$. 


\begin{tabular}{cc}
$\rho$ & $\boldsymbol{p m}(\rho)$ \\
\hline$\{1 \mathrm{sg}\}$ & $\{1 A\}$ \\
$\{2 \mathrm{sg}\}$ & $\{2 B\}$ \\
$\{3 \mathrm{sg}\}$ & $\{3 A\}$ \\
$\{1 \mathrm{du}\}$ & $\{1 \mathrm{du}\}$ \\
$\{2 \mathrm{du}\}$ & $\{2 \mathrm{du}\}$ \\
$\{3 \mathrm{du}\}$ & $\{3 \mathrm{du}\}$ \\
$\{1 \mathrm{pl}\}$ & $\{1 B\}$ \\
$\{2 \mathrm{pl}\}$ & $\{2 A\}$ \\
$\{3 \mathrm{pl}\}$ & $\{3 A\}$ \\
\hline
\end{tabular}

(12) Formal analysis of Hua agreement inflections

(a) Paradigm function:

$\operatorname{PF}(\langle\mathrm{Z}, \sigma\rangle)=[$ iii : [ ii : [ i : $\langle\mathrm{Z}, \boldsymbol{p} \boldsymbol{m}(\sigma)\rangle]]]$

(b) Realization rules

\begin{tabular}{|c|c|}
\hline Block i & $\begin{array}{l}X, \text { Verb, }\{1\} \rightarrow X^{\prime} \text {, the result of the following ablaut operation on } X: \\
\quad \text { root vowel } \rightarrow[- \text { front }] \\
\begin{array}{r}X, \text { Verb, }\{2\} \rightarrow X^{\prime} \text {, the result of the following ablaut operation on } X: \\
\quad[- \text { front }] \text { root vowel } \rightarrow[+ \text { low }]\end{array} \\
\begin{array}{r}X, \text { Verb, }\{3\} \rightarrow X^{\prime} \text {, the result of the following ablaut operation on } X: \\
\text { root vowel } \rightarrow[+ \text { front }]\end{array}\end{array}$ \\
\hline Block ii & $X$, Verb, $\{$ dual $\} \rightarrow X^{\prime}$ \\
\hline Block iii & $\begin{array}{ll}\mathrm{X}, \text { Verb, }\{\text { interrogative }\} & \rightarrow \text { Xve } \\
\mathrm{X}, \text { Verb, }\{\text { interrogative, } B\} & \rightarrow \text { Xpe } \\
\mathrm{X}, \text { Verb, }\{\text { exclamatory } & \rightarrow \text { Xmana } \\
\mathrm{X}, \text { Verb, }\{\text { exclamatory, } B\} & \rightarrow \text { Xpana } \\
\text { etc. } & \end{array}$ \\
\hline
\end{tabular}

(13) a. $[[\{\mathrm{sg}\} \wedge[\{1\} \vee\{3\}]] \vee[\{\mathrm{pl}\} \wedge[\{2\} \vee\{3\}]]]$

b. $[\{2 \mathrm{sg}\} \vee\{1 \mathrm{pl}\}]$

Because the class of forms associated with the morphome $\mathrm{B}$ is not syntactically or semantically coherent, each of the rules realizing this morphome is polyfunctional. 


\section{Polyfunctionality across categories: Cross-categorial recurrence}

An inflectional rule may realize the same set of properties in the inflection of lexemes belonging to distinct syntactic categories; in doing so, it may participate in the realization of two distinct kinds of content. This source of polyfunctionality is represented schematically in Figure 6 . This source of polyfunctionality is different from shared exponence, since here, the polyfunctional exponent always expresses the same content; its polyfunctionality stems from the fact that this content has different significance in the inflection of different categories of lexemes. Cross-categorial recurrence also differs from directional syncretism: the latter is the property of an inflectional paradigm in which the realization of one cell patterns after that of another cell; but cross-categorial recurrence involves similarities among distinct paradigms in distinct categories.

FIGURE 6 Polyfunctionality across categories arising from cross-categorial recurrence

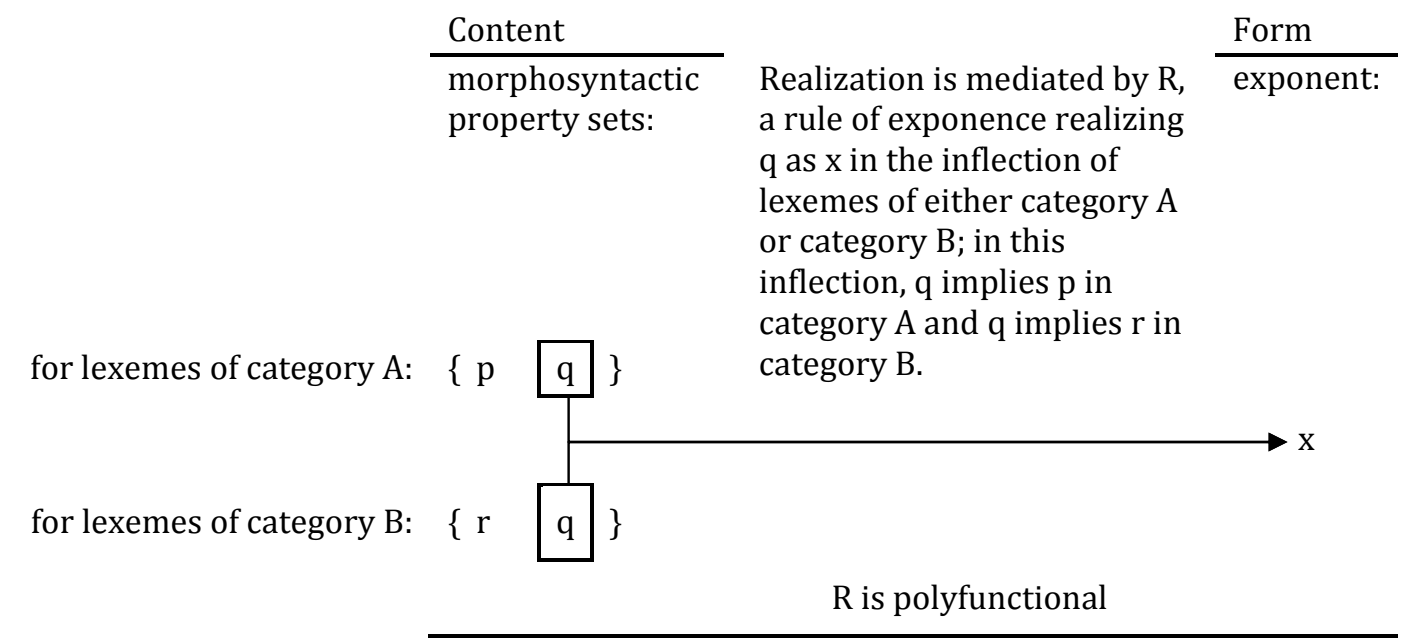

Consider, for example, the inflection of possessed nouns and transitive verbs in Khanty (Uralic: Russian [Khantia-Mansia Autonomous Region]). Possessed nouns inflect for the number of the possessum and for the possessor's person and number; transitive verbs inflect for the number of the object and for the person and number of the subject. As the examples in Table 4 show, these two subsystems of agreement inflection employ substantially the same morphology; the "exploded" versions of these paradigms in Table 5 make this similarity particularly clear. One can account for this overlap by assuming that many of the rules that express Khanty agreement are insensitive to the distinc- 
tion between subject properties and possessor properties and between object properties and possessum properties.

TABLE 4 Person/number inflection in Khanty nouns and verbs (Nikolaeva 1999)

\begin{tabular}{|c|c|c|c|c|}
\hline & \multicolumn{4}{|c|}{$\begin{array}{l}\text { Possessor/possessum inflection } \\
\text { of X0:T 'house' }\end{array}$} \\
\hline & & \multicolumn{3}{|c|}{ Possessum } \\
\hline & & SINGULAR & DUAL & PLURAL \\
\hline \multirow{3}{*}{$\begin{array}{l}\mathrm{P} \\
\mathrm{o} \\
\mathrm{c}\end{array}$} & 1SG & xo:te:m & xo:tyilam & xo:tlam \\
\hline & $2 S G$ & xo:te:n & xo:tyilan & xo:tlan \\
\hline & 3SG & $x o: t l$ & xo:trilal & xo:tlal \\
\hline \multirow{6}{*}{$\begin{array}{l}\mathrm{s} \\
\mathrm{e} \\
\mathrm{s} \\
\mathrm{s} \\
\mathrm{o} \\
\mathrm{r}\end{array}$} & $1 \mathrm{DU}$ & xo:te:man & xo:tyilman & xo:tlaman \\
\hline & 2DU & xo:tlan & xo:ţillan & xo:tlalan \\
\hline & 3DU & xo:tlan & xo:tyillan & xо:tlalan \\
\hline & 1PL & xo:te:w & xo:tᄁiluw & xo:tluw \\
\hline & $2 \mathrm{PL}$ & xo:tlan & xo:tyillan & xo:tlalan \\
\hline & 3PL & xo:te:l & xo:tyilal & xo:tlal \\
\hline
\end{tabular}

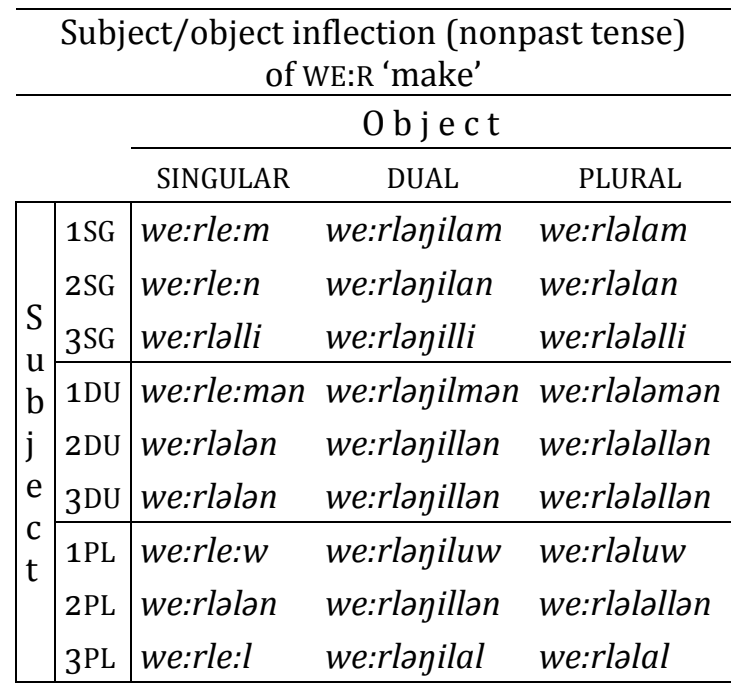

Thus, suppose that the morphosyntactic properties of a possessed noun are situated in two layers ${ }^{6}$, with the possessor's person and number in the outer layer and the number of the possessum in the inner layer; suppose, in addition, that a transitive verb's morphosyntactic properties are likewise situated in two layers, with subject person and number in the outer layer and object number in the inner layer. On these assumptions, the agreement properties of possessed nouns parallel those of transitive verbs, as in (14). Accordingly, the inflectional realization of a possessed noun's properties parallels that of a transitive verb's properties, involving many of the same rules of exponence - rules whose application is insensitive to the distinction between nouns and verbs, between subjects and possessors, or between objects and possessa. The relevant rules may be formulated as in the formal analysis in (15), where each block of rules determines the morphology of one of the four affix positions distinguished in the "exploded" paradigms in Table 5 .

(14) Layering of morphosyntactic properties in Khanty

\footnotetext{
${ }^{6}$ See (Anderson 1992: 94) for a formal proposal for the definition of this sort of layering.
} 
TABLE 5 Person/number inflection in Khanty nouns and verbs (exploded view)

\begin{tabular}{|c|c|c|c|c|c|c|c|c|c|c|c|c|c|}
\hline \multicolumn{7}{|c|}{$\begin{array}{c}\text { Possessor/possessum inflection } \\
\text { of X0:T 'house' }\end{array}$} & \multicolumn{7}{|c|}{$\begin{array}{l}\text { Subject/object inflection (nonpast tense) } \\
\text { of WE:R 'make' }\end{array}$} \\
\hline POSSESSUM & POSSESSOR & & $\mathrm{i}$ & ii & iii & iv & & $\mathrm{i}$ & ii & iii & iv & SUBJECT & ОВJЕСТ \\
\hline \multirow[t]{9}{*}{ SG } & $1 \mathrm{SG}$ & $x o: t$ & & $-e:$ & $-m$ & & we:rl & & $-e:$ & $-m$ & & $1 \mathrm{SG}$ & $S G$ \\
\hline & $2 S G$ & $x o: t$ & & $-e:$ & & $-n$ & we:rl & & $-e$ : & & $-n$ & $2 S G$ & \\
\hline & $3 S G$ & $x o: t$ & & & -1 & & we:rla & & & $-l$ & -li & 3SG & \\
\hline & 1DU & xo:t & & $-e:$ & $-m a$ & $-n$ & we:rl & & $-e:$ & $-m a$ & $-n$ & $1 \mathrm{DU}$ & \\
\hline & $2 \mathrm{DU}$ & $x o: t$ & & & -la & $-n$ & we:rla & & & -la & $-n$ & $2 \mathrm{DU}$ & \\
\hline & $3 \mathrm{DU}$ & $x o: t$ & & & -la & $-n$ & we:rla & & & $-l a$ & $-n$ & 3DU & \\
\hline & $1 \mathrm{PL}$ & $x o: t$ & & $-e:$ & $-w$ & & we:rl & & $-e:$ & $-w$ & & 1PL & \\
\hline & $2 \mathrm{PL}$ & xo:t & & & -la & $-n$ & we:rla & & & $-l a$ & $-n$ & $2 \mathrm{PL}$ & \\
\hline & 3PL & $x o: t$ & & $-e:$ & -1 & & we:rl & & $-e:$ & -1 & & 3PL & \\
\hline \multirow[t]{9}{*}{ DU } & $1 \mathrm{SG}$ & $x o: t$ & $-\eta$ il & $-a$ & $-m$ & & we:rla & $-\eta$ il & $-a$ & $-m$ & & $1 \mathrm{SG}$ & $D U$ \\
\hline & $2 \mathrm{SG}$ & $x o: t$ & $-\eta$ il & $-a$ & & $-n$ & we:rla & $-\eta$ il & $-a$ & & $-n$ & $2 \mathrm{SG}$ & \\
\hline & $3 \mathrm{SG}$ & $x o: t$ & $-\eta$ il & $-a$ & $-l$ & & we:rla & $-\eta$ il & & -1 & -li & 3SG & \\
\hline & $1 \mathrm{DU}$ & xo:t & $-\eta$ il & & $-m a$ & $-n$ & we:rla & $-\eta$ il & & $-m a$ & $-n$ & $1 \mathrm{DU}$ & \\
\hline & $2 \mathrm{DU}$ & $x o: t$ & $-\eta$ il & & -la & $-n$ & we:rla & $-\eta$ il & & -la & $-n$ & $2 \mathrm{DU}$ & \\
\hline & $3 \mathrm{DU}$ & xo:t & $-\eta$ il & & -la & $-n$ & we:rla & $-\eta$ il & & -la & $-n$ & 3DU & \\
\hline & 1PL & $x o: t$ & $-\eta$ il & & $-u w$ & & we:rla & $-\eta$ il & & $-u w$ & & $1 \mathrm{PL}$ & \\
\hline & $2 \mathrm{PL}$ & $x o: t$ & $-\eta$ il & & -la & $-n$ & we:rla & $-\eta$ il & & $-l a$ & $-n$ & $2 \mathrm{PL}$ & \\
\hline & 3PL & xo:t & $-\eta$ il & $-a$ & $-l$ & & we:rla & $-\eta$ il & $-a$ & -1 & & 3PL & \\
\hline \multirow[t]{9}{*}{ PL } & $1 \mathrm{SG}$ & $x o: t$ & -1 & $-a$ & $-m$ & & we:rla & $-I$ & $-a$ & $-m$ & & $1 S G$ & $P L$ \\
\hline & $2 \mathrm{SG}$ & xo:t & -1 & $-a$ & & $-n$ & we:rla & -1 & $-a$ & & $-n$ & $2 S G$ & \\
\hline & $3 S G$ & $x o: t$ & -1 & $-a$ & -1 & & we:rla & -la & & -1 & $-l i$ & 3SG & \\
\hline & 1DU & $x o: t$ & -la & & $-m a$ & $-n$ & we:rla & $-l a$ & & $-m a$ & $-n$ & 1DU & \\
\hline & $2 \mathrm{DU}$ & $x o: t$ & $-l a$ & & -la & $-n$ & we:rla & $-l a$ & & -lla & $-n$ & $2 \mathrm{DU}$ & \\
\hline & 3DU & $x o: t$ & -la & & -la & $-n$ & we:rla & -la & & -lla & $-n$ & 3DU & \\
\hline & $1 \mathrm{PL}$ & $x o: t$ & -1 & & $-u w$ & & we:rla & $-I$ & & $-u w$ & & 1PL & \\
\hline & $2 \mathrm{PL}$ & $x o: t$ & $-l a$ & & -la & $-n$ & we:rla & $-l a$ & & -lla & $-n$ & $2 \mathrm{PL}$ & \\
\hline & 3PL & $x o: t$ & -1 & $-a$ & -1 & & we:rla & $-l$ & $-a$ & -1 & & 3PL & \\
\hline
\end{tabular}

$$
\text { "outer" properties }
$$

Nouns: $\{\overline{\text { possessor person number }}\{\overline{\text { possessum number }}\}$ 
(15) Formal analysis of Khanty person/number inflections ${ }^{7}$

a. Paradigm function

$\operatorname{PF}(\langle\mathrm{X}, \sigma:\{2[$ dual $\vee \mathrm{pl}]\}\rangle) \Rightarrow \sigma /\{3$ dual $\}$;

otherwise, $\operatorname{PF}(\langle\mathrm{X}, \sigma\rangle)=[$ iv : [ iii : $[$ ii : $[\mathrm{i}:\langle\mathrm{X}, \sigma\rangle]]]]$

b. Rules of exponence

\section{Block i}

$\mathrm{X},[],\{\{$ dual $\}\} \rightarrow \mathrm{X} \eta$ il

$\mathrm{X},[],\{\{\mathrm{pl}\}\} \rightarrow \mathrm{Xla}$

\section{Block ii}

$\mathrm{X},[],\{[[1 \vee[2 \mathrm{sg}]] \vee[3 \mathrm{pl}]]\{\mathrm{sg}\}\} \rightarrow \mathrm{Xe:}$

$\mathrm{X},[],\{[\mathrm{sg} \vee[3 \mathrm{pl}]]\{[\mathrm{dual} \vee \mathrm{pl}]\}\} \rightarrow \mathrm{X} a$

$\mathrm{X}$, Verb, $\{3 \mathrm{sg}\} \rightarrow \mathrm{X}$

\section{Block iii}

$\mathrm{X},[],\{1\} \rightarrow \mathrm{Xm}$

$\mathrm{X},[],\{1 \mathrm{pl}\} \rightarrow \mathrm{Xuw}$

$X,[],\{3\} \rightarrow X l$

$\mathrm{X}$, Verb, $\{3$ dual $\{\mathrm{pl}\}\} \rightarrow \mathrm{X} l l$

\section{Block iv}

$\mathrm{X},[],\{[2 \vee$ dual $]\} \rightarrow \mathrm{Xn}$

$\mathrm{X}$, Verb, $\{3 \mathrm{sg}\} \rightarrow \mathrm{Xli}$

According to this analysis, the realization of a Khanty noun form's possessor and possessum properties is generally accomplished by the same rules of exponence as the realization of a verb form's subject and object properties, as for example in Table 6 . When a rule of this sort realizes an "outer" property p or an "inner" property q in the inflection of a noun, the implication is that $\mathrm{p}$ is a possessor property and $\mathrm{q}$, a possessum property; when this same rule realizes $\mathrm{p}$ or $\mathrm{q}$ in the inflection of a verb, the implication is that $\mathrm{p}$ is a subject property and $\mathrm{q}$, an object property. For this reason, each of the unspecific rules of exponence in (15b) is polyfunctional.

\section{Conclusions}

In each of the foregoing examples, the same rule of exponence is used to express more than one kind of content. Sometimes this leads to ambiguity; but it invariably leads to a kind of economy in the inflectional system, reducing the number of exponents required to express the system's morphosyntactic contrasts. Like many morphological phenomena, inflectional polyfunctionality arises in a variety of ways. In theoretical terms, these include

\footnotetext{
ciples (ii)-(iv):

(i) $\mathrm{X}$, [], \{\} $\rightarrow \mathrm{X}$ (cf. Stump 2001: 53, 143)

(ii) $ə$ elides prevocalically

(iii) postvocalically, $\mathrm{u} w \rightarrow w$

(iv) word finally, $\mathrm{C} 1 \mathrm{C} 2 \rightarrow \mathrm{C} 1 ə \mathrm{C} 2$
}

${ }^{7}$ This analysis assumes the Identity Function Default (i) as well as sandhi prin- 
TABLE 6 Recurring exponents in Khanty nominal and verbal inflection

\begin{tabular}{|c|c|c|c|}
\hline & & $\begin{array}{l}\text { paradigm: } \mathrm{xO}: \mathrm{T} \text { 'house' } \\
\text { cell: 'the two houses of us two' } \\
\langle x o: t, \sigma:\{\text { psr } 1 \text { dual }\{\mathrm{psm} \text { dual }\}\}\rangle\end{array}$ & $\begin{array}{l}\text { paradigm: WE: } \mathrm{R} \text { 'make' } \\
\text { cell: 'we two make those two' } \\
\langle\text { we:rla. } \tau:\{\text { sbi } 1 \text { dual }\{\text { obj dual }\}\}\rangle\end{array}$ \\
\hline Block & Rule & $\langle x o: t, \sigma:\{$ psr 1 dual $\{$ psm dual $\}\}\rangle$ & $\langle$ we:rla, $\tau:\{$ sbj 1 dual \{obj dual $\}\}\rangle$ \\
\hline $\mathrm{i}$ & $\mathrm{X},[],\{\{$ dual $\}\} \rightarrow$ X il & $\langle x o: t \eta i l, \sigma\rangle$ & $\langle$ we:rlayil, $\tau\rangle$ \\
\hline ii & IFD & n. c. & n. c. \\
\hline iii & $\mathrm{X},[],\{1\} \rightarrow \mathrm{Xm}$ & $\langle x o: t \eta i l m, \sigma\rangle$ & $\langle$ we:rlayilm, $\tau\rangle$ \\
\hline iv & $\mathrm{X},[],\{[2 \vee$ dual $]\} \rightarrow \mathrm{X} n$ & $\langle x o: t \eta i l m a n, \sigma\rangle$ & $\langle$ we:rlayilman, $\tau\rangle$ \\
\hline
\end{tabular}

- simple homophony (Two rules of exponence introduce homophonous exponents.)

- rule invitation (Rules of referral cause the same rule of exponence to apply in different positions in the realization of distinct but related property sets; although the application of the rule itself is conditioned by the same set of properties in both positions, the properties conditioning its invitation to one position differ from those for the other position. In this way, the rule of exponence is polyfunctional.)

- referral (A rule of referral causes the realization of one cell to follow that of another cell. The rules of exponence involved in this realization are therefore polyfunctional, expressing one sort of content directly and another sort indirectly, by referral.)

- disjunctive exponence (A rule of exponence realizes a constraint satisfied by more than one set of properties; the rule is therefore polyfunctional.)

- realization of a morphomic property (Distinct morphosyntactic properties are associated with the same morphomic property, so that the rule of exponence realizing this morphomic property is polyfunctional.)

- cross-categorial recurrence (A rule of exponence realizes a set of morphosyntactic properties that are associated with more than one category of lexemes; although the rule itself applies indiscriminately with respect to this category difference, its application entails a different set of coincident properties in each category. In this way, the rule of exponence is polyfunctional.)

Besides reducing the number of distinct exponents involved in the realization of a language's inflected forms, polyfunctionality in some cases heightens the predictability of unencountered forms as well as the frequency (and perhaps, therefore, the memorability or processing ease) of 
particular word forms or formatives. For example, if a polyfunctional exponent causes distinct cells in a lexeme's paradigm to be realized alike, then encountering that exponent in a novel form serving one of the syncretized functions allows an identical form serving the other function to be immediately inferred. By the same token, words in different categories that employ the same morphology to express different kinds of agreement relationships are mutually reinforcing: both contribute to the frequency of the same fundamental inflectional pattern. Polyfunctional rules of exponence seemingly enhance word forms' ease of storage and/or processing to an extent that outweighs any difficulties for learning or processing created by the potential ambiguity of polyfunctional exponents.

\section{References}

Anderson, S.R. 1992. A-morphous Morphology. Cambridge Studies in Linguistics. Cambridge University Press.

Aronoff, Mark. 1994. Morphology by itself. Cambridge: MIT Press.

Ashton, E.O. 1944. Swahili grammar. Essex: Longman.

Gazdar, Gerald, Geoffrey K. Pullum, Robert Carpenter, Ewan Klein, Thomas E. Hukari, and Robert D. Levine. 1988. Category structures. Computational Linguistics 14(1):1-19.

Haiman, J. 1980. Hua, a Papuan language of the eastern highlands of New Guinea. Studies in language companion series. John Benjamins.

Nikolaeva, Irina. 1999. Ostyak. LINCOM Europa.

Soukka, M. 2000. A descriptive grammar of Noon: a Cangin language of Senegal. LINCOM studies in African linguistics. LINCOM Europa.

Stump, Gregory. 2013. A micromorphological approach to variable affix order. In required. San Diego: Paper presented at the 2nd American International Morphology Meeting, University of California.

Stump, Gregory T. 2001. Inflectional Morphology: A theory of paradigm structure. Cambridge Studies in Linguistics. Cambridge University Press.

Whitney, William Dwight. 1889. Sanskrit Grammar [2 ${ }^{\text {nd }}$ Edition]. Cambridge, MA: Harvard University Press. 